\title{
Impact of Proximity Effects on Sheath Losses in Trefoil Cable Arrangements
}

\author{
Dimitrios Chatzipetros, Student Member, IEEE and James A. Pilgrim, Senior Member, IEEE
}

\begin{abstract}
Induced losses are a significant part of the total losses generated in HVAC cables. Presently, IEC 60287-1-1 is used to calculate the ratio of induced loss in a cable's metal sheath to its conductor loss $\left(\lambda_{1}\right)$, assuming uniform current density in both conductors and sheaths. Although this assumption is reasonable for smaller cables, it is questionable for larger cables in close proximity, such as three-core (3C) export cables in Offshore Wind Farm (OWF) projects. The effects of this non-uniform current density cannot be easily treated via a straightforward, purely analytical approach, since conductor currents are not effectively represented by linear ones in larger cables, while sheath currents are also unevenly distributed. The present study employs 2-D Finite Element (FE) models to evaluate how accurate the Standard method for calculating the $\lambda_{1}$ factor is in cables with non-magnetic armor. Their validity is further enhanced by means of Filament Method. IEC 60287 appears to overestimate the temperature, particularly for larger conductor sizes, by up to $7^{\circ} \mathrm{C}(8 \%)$. Finally, suitable Reductive Factors are suggested which could improve the accuracy of the IEC method.
\end{abstract}

Index Terms-- Current rating, Numerical modeling, Power transmission, Submarine cables, Induced losses, Proximity effect

\section{INTRODUCTION}

$\mathrm{T}$ HE cost of a cable circuit is partly determined by the conductor size, and is often crucial for the viability of projects such as Offshore Wind Farms (OWFs). To optimize the cable size, an accurate calculation of losses is required. In HVAC cables, the currents induced in metallic sheaths yield extra heat losses, thus further contributing to the temperature rise of the conductor. These induced losses are currently treated by IEC $60287-1-1$ by means of the factor $\lambda_{1}$ [1]. The existing method does not consider proximity effects when calculating $\lambda_{1}$, meaning that the accuracy may be reduced for individually sheathed cables in close physical proximity. The distribution of current density $J$ in the conductors will affect sheath losses. Fig. 1 shows the ohmic losses in the sheaths when non-uniform $J$ in $1000 \mathrm{~mm}^{2}$ conductors is considered. If uniform $J$ was considered, ohmic losses would be $20 \%$ higher and the maximum loss density would be equal to $7105.8 \mathrm{~W} / \mathrm{m}^{3}$.

This paper studies the influence of proximity effects on sheath losses when Single-Core (1C) cables are laid in trefoil, and for three-core (3C) submarine cables without magnetic

This work was supported by Cablel® Hellenic Cables S.A., Viohalko Group (http://www.cablel.com/).

D. Chatzipetros is with the School of Electronics and Computer Science (ECS), University of Southampton, SO17 1BJ, U.K. and also with the Cablel ® Hellenic Cables S.A., Viohalko Group, 41 Olimpionikou Tsiklitira, GR 15125 Maroussi, Athens, Greece (e-mail: dc2r15@soton.ac.uk). armor. Losses are studied by means of 2-D Finite Element Method (FEM), which is considered a black-box approach, and Filament Method (FM), which is a more readily understandable one. The former is used as a reference in order to review the existing analytical equations. Reductive Factors (RFs) are proposed, which could improve the accuracy of the IEC calculations, based on the parametric analysis done.

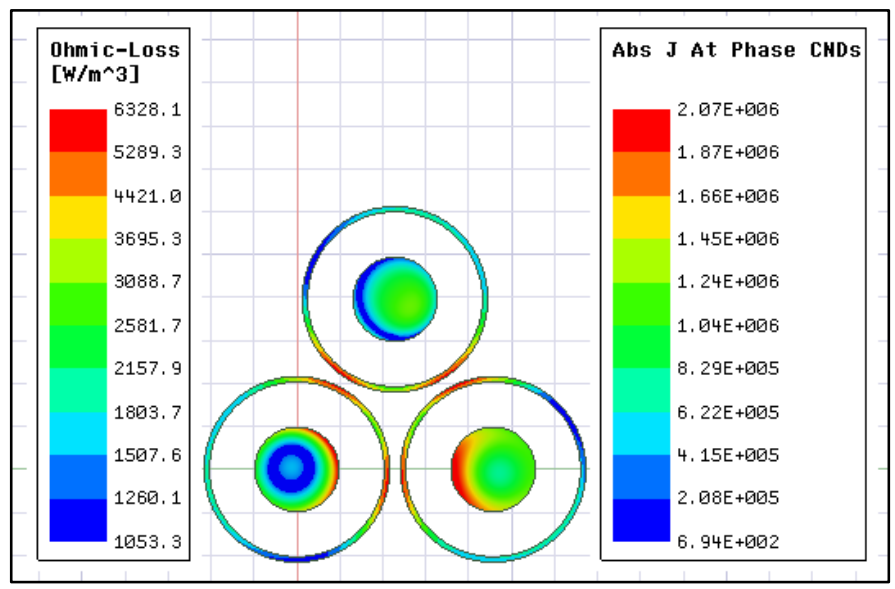

Fig. 1. Ohmic loss density $\left(\mathrm{W} / \mathrm{m}^{3}\right)$ in sheaths (color code on the left) for uneven $J\left(\mathrm{~A} / \mathrm{m}^{2}\right)$ in conductors (color code on the right) at phase angle $0^{\circ}$.

\section{II. "TYPES” OF INDUCED LOSSES IN SHEATHS}

Losses induced in sheaths can be divided into two groups, depending on the type of bonding: losses mainly due to circulating currents flowing in sheaths if they are Solidly Bonded (SB), and those caused by eddy currents circulating radially and azimuthally for Single-Point Bonded (SPB) sheaths. As Anders points out [2], eddy current loss occurs irrespective of the bonding method, although it is often ignored in solidly bonded sheaths where it is assumed small in magnitude compared to circulating current loss. This section reviews the Standard formulae and their origins.

\section{A. Eddy Current Loss}

Sheath eddy currents of $1^{\text {st }}$ order occur as a result of the combined effect of the internal conductor current and the external currents in neighboring cables. Eddies local to the sheath wall only (self-induced currents) are generated by the

J. A. Pilgrim is with the School of Electronics and Computer Science (ECS), University of Southampton, SO17 1BJ, U.K. (e-mail: jp2@ecs.soton.ac.uk).

All data supporting this study are openly available from the University of Southampton repository at: http://dx.doi.org/10.5258/SOTON/D0780 
former, while currents circulating from wall to wall of the same sheath occur by the latter. Self-induced currents are in practice negligible. A $2^{\text {nd }}$ order eddy current arises from the effect of the magnetic field of $1^{\text {st }}$ order eddies in neighboring sheaths and the process continues until the successive order eddies have negligible effect [3] in the sheath considered.

\section{1) Jackson's Method:}

The most precise analytical approach was provided by Jackson in 1975 [3]. He successfully extended Carter's earlier work [4] accounting for higher order eddy currents by means of formulae including infinite series. The $1^{\text {st }}$ order loss factor in terms of external currents is shown in (1) assuming $1 \mathrm{C}$ cables in trefoil spaced formation with three-phase balanced currents.

$$
\lambda_{1 s t}^{\prime \prime}=\frac{R_{S}}{R} \sum_{n=1}^{\infty}\left[2\left(\frac{d}{2 s}\right)^{2 n} \frac{m^{2}}{n^{2}+m^{2}}\left(2-\cos \frac{n \pi}{3}\right)\right]
$$

where $R_{\mathrm{S}}$ is the resistance of sheath per unit length (pul) of cable $(\Omega / \mathrm{m}), R$ is the ac resistance of conductor pul $(\Omega / \mathrm{m}), d$ is the mean diameter of sheath $(\mathrm{mm}), s$ is the distance between conductor axes $(\mathrm{mm})$ and $m$ is the frequency to resistance dimensionless ratio given by (2):

$$
m=\frac{\omega}{R_{S}} \cdot 10^{-7}
$$

where $\omega$ is the angular frequency ( $\left.\mathrm{rad} \cdot \mathrm{s}^{-1}\right)$. Although (1) appears to be accurate enough for widely spaced cables and small $m$ values, i.e. less conductive sheaths (e.g. Lead), considerable errors of up to $20 \%$ may occur for cables in close formation, or those with more conductive sheaths (e.g. Aluminium) if higher order eddy currents are excluded [3]. $2^{\text {nd }}$ or higher order eddy current loss factors consist of multiple infinite series, and as shown by Jackson [3], the effect of $4^{\text {th }}$ and higher order currents can usually be neglected.

\section{2) IEC 60287-1-1 - ERA Method:}

The report published by ERA [5] suggests an empirical method based on the previous work published by Heyda [6], which comprises tabulated values. As reported in [5], these are in an excellent agreement with Jackson's method. Although Jackson's work is recognized as valuable and very accurate, the computation of infinite series was a laborious task in 1979. Hence, a simpler method suitable for hand calculation is proposed by [5]. ERA's method has been adopted by IEC 60287 and is currently used to calculate eddy current losses in singlepoint bonded sheaths. The relevant formulae are presented in the following equations for $1 \mathrm{C}$ cables in triangular formation:

$$
\lambda_{1, \mathrm{IEC}}^{\prime \prime}=\frac{R_{\mathrm{S}}}{R}\left[g_{\mathrm{S}} \lambda_{0}\left(1+\Delta_{1}+\Delta_{2}\right)+\frac{\left(\beta_{1} t_{\mathrm{S}}\right)^{4}}{12 \cdot 10^{12}}\right]
$$

where $t_{\mathrm{S}}$ is the thickness of sheath $(\mathrm{mm})$ and

$$
\begin{gathered}
g_{\mathrm{S}}=1+\left(\frac{t_{\mathrm{S}}}{D_{\mathrm{S}}}\right)^{1.74}\left(\beta_{1} D_{\mathrm{S}} \cdot 10^{-3}-1.6\right) \\
\lambda_{0}=3\left(\frac{m^{2}}{1+m^{2}}\right)\left(\frac{d}{2 s}\right)^{2} \\
\Delta_{1}=\left(1.14 m^{2.45}+0.33\right)\left(\frac{d}{2 s}\right)^{0.92 m+1.66} \\
\beta_{1}=\sqrt{\frac{4 \pi \omega}{10^{7} \rho_{\mathrm{S}}}}
\end{gathered}
$$

where $D_{\mathrm{S}}$ is the external diameter of cable sheath $(\mathrm{mm}), \rho_{\mathrm{S}}$ is the electrical resistivity of sheath material $(\Omega \cdot \mathrm{m})$ and $\Delta_{2}=0$ for $1 \mathrm{C}$ cables in trefoil formation. It is readily noticeable that the sum factor in (1) leads to (5) for $n=1$. Term $\Delta_{1}$ is expected to approximate the infinite series derived by Jackson's paper [3].

The assumption that the conductor current is concentrated along the longitudinal axis of the sheath is implied in both (1) and (3). Although expected to be representative enough for small or spaced conductors, it may not hold for larger conductors in trefoil. The external magnetic field produced by the three conductor currents is actually reduced by the crowding of the currents towards each other, as Arnold notes [7]; hence, (1) and (3) may become conservative for larger conductor sizes, as the present paper demonstrates. Heyda considers the likely impact of the proximity effects in [6] but assumes them to be insignificant, owing to the possible use of Milliken conductors for higher power demands. Presently, Milliken conductors are rarely used for $3 \mathrm{C}$ subsea cables due to the practical difficulties in providing sufficient water blocking capability and the increase in cable size that complicates the installation stage.

\section{B. Circulating Current and Total Losses - IEC 60287-1-1}

When sheaths are solidly bonded, induced currents flow in one direction along one sheath, returning along another one. The formulae adopted by IEC 60287 date back to the work published by Arnold [8] and are presented in this section for three $1 \mathrm{C}$ cables in trefoil formation.

$$
\lambda_{1, \mathrm{IEC}}^{\prime}=\frac{R_{\mathrm{S}}}{R} \frac{1}{1+\left(\frac{R_{\mathrm{S}}}{X}\right)^{2}}
$$

where $X$ is the reactance pul of sheath $(\Omega / m)$, i.e.

$$
X=2 \omega 10^{-7} \ln \left(\frac{2 s}{d}\right)
$$

Total losses in the sheath consist of losses caused by circulating and eddy currents and the respective factor is shown in (10) [1].

$$
\lambda_{1, \mathrm{IEC}}=\lambda_{1, \mathrm{IEC}}^{\prime}+\lambda_{1, \mathrm{IEC}}^{\prime \prime}
$$

Although eddy current loss is important for single-point bonded sheaths, it becomes less significant when solidly 
bonded sheaths are considered, as already cited by Anders [2]. IEC $60287-1-1$ has adopted this view, by neglecting $\lambda_{1, \mathrm{IEC}}$ " for solid bonding cases. However, $\lambda_{1, \mathrm{IEC}}$ " may become significant for cables laid in close proximity, whereas $\lambda_{1, \mathrm{IEC}}$ ' is minimized for touching formation. Assuming three cables of outer diameter $d_{\mathrm{e}}$ with a $\mathrm{Cu}$ conductor of radius equal to $20 \mathrm{~mm}$ and an $\mathrm{Al}$ sheath of $t_{\mathrm{S}}=1 \mathrm{~mm}, \lambda_{1, \mathrm{IEC}}$ " rises from about 0.04 to 0.3 when reducing from $s=3 d_{\mathrm{e}}$ to $s=d_{\mathrm{e}}$ (touching) and at the same moment $\lambda_{1, \text { IEC' }}=0.8$ for $s=d_{\mathrm{e}}$. Therefore, $\lambda_{1, \mathrm{IEC}}$ " and $\lambda_{1, \mathrm{IEC}}$ ' may not be so incomparable and the omission of eddy current loss appears to be questionable for cables in touching arrangement.

Furthermore, (8) accounts only for the sheath dc resistance, implying uniformly distributed sheath current $I_{S}$. However, Arnold cites in [8] that uneven distribution of $I_{\mathrm{S}}$ is expected in sheaths of neighboring cables. The closer the cables are laid to one another, the greater the variation in the induced emf along the sheath circumference and the more uneven the distribution of $I_{\mathrm{S}}$ will be. More recently, Kovač [9] has taken this into account via FM when calculating sheath losses for solidly bonded cables laid in touching, flat formation. However, he neglected the uneven current distribution in conductors, assuming they could be sufficiently represented by a single filament. It is shown in the present paper that for large conductor sizes, where the proximity effect within the conductor is not negligible, this assumption does not hold true. Similar conclusions are made by Ferkal [10], who implemented an analytical approach: discrepancies up to $16 \%$ against methods neglecting the effect of the conductor when evaluating the screen losses are reported for a conductor of radius 22.56 $\mathrm{mm}$.

\section{Filament Method (FM)}

\section{A. Method Description}

FM relies on physically representing the metallic parts of a $3 \mathrm{C}$ cable by means of a number of thinner cylindrical wires (or filaments), each one carrying a uniform current density (no skin and proximity effects). The current in each filament is not known in advance; however, the total sum of filament currents must be equal to the total conductor or sheath current. The interaction between filaments is represented by their self and mutual inductances. One of the earliest works is published by Comellini [11], who considers also the effect of soil impedance. Kovač [12] employs a similar formulation and he additionally demonstrates that modeling of the ground return path is not necessary when dealing with loss calculations. Hence, a formulation similar to that of Moutassem [13] is derived, which is also referred to [2]. This latter version is employed in the present paper. Only the final equation is shown in (11) to save space; $\mathbf{I}$ is the vector of $n$ filament currents (A), $\mathbf{R}_{d}$ is a diagonal $n$ x $n$ matrix representing $R_{i}$, namely the dc resistance of filament " $i$ " $(\Omega / \mathrm{m}), \mathbf{G}$ is the inductance matrix of size $n \times n$ with elements equal to $\ln \left(1 / s_{i j}\right)$, where $s_{i j}$ is the distance between filaments " $i$ " and " $j$ " $(\mathrm{m}), \mathbf{M}$ is the connection matrix $(m \times n)$, where $m$ is the number of conductors and sheaths in total (they are in general called composites) and $\mathbf{I}^{\mathbf{c}}$ is the vector of $m$ composite currents (A). $\mathbf{I}^{\mathbf{c}}$ is known in advance, because composite conductor currents are given, while composite sheath currents may be zero and non-zero for single-point and solid bonding cases, respectively. In the latter case sheath currents have to be calculated as described by Anders [2] in $\S 8.5 /(8.133)$. The remaining quantities are all known except for I, which is the unknown vector to be solved for. The reader is referred to [13] and [2] to obtain the full description of the method.

\section{B. Comparison VS 2-D FE models}

FE models have been employed since the late 1980s for the calculation of induced losses in cables, such as [14]. They are also used as benchmarking tools for simpler, analytical models, such as [13] and [15]. In this section, the use of (11) is verified against FE models; results are shown in Table I for copper conductor, lead sheathed cables, laid in trefoil, close formation, with conductor radius $r_{\mathrm{C}}$, sheath inner radius $r_{\mathrm{S} \text {,in }}$ and thickness $t_{\mathrm{S}}$. Tests for both $\lambda_{1}$ " and $\lambda_{1}$ cases are presented. As shown in the $3^{\text {rd }}$ and $4^{\text {th }}$ columns of Table I, the \% relative difference between FE and FM models, i.e. $e_{\mathrm{FE}, \mathrm{FM}}$, is kept fairly low for $660 \leq n \leq 760$. Better accuracy is obtained, as expected, for $2560 \leq n \leq 2950$, as shown in the $6^{\text {th }}$ and $7^{\text {th }}$ columns of Table I.

TABLE I

FM VS FE MODELS FOR VARIOUS CABLE SIZES AND NUMBER OF FILAMENTS

\begin{tabular}{|c|c|c|c|c|c|c|}
\hline $\begin{array}{c}r_{\mathrm{C}} / r_{\mathrm{S}, \mathrm{in}} / t_{\mathrm{S}} \\
{[\mathrm{mm}]}\end{array}$ & $n$ & $\begin{array}{c}e_{\mathrm{FE}, \mathrm{FM}}, \\
\lambda_{1}{ }{ }^{2}[\%]\end{array}$ & $\begin{array}{c}e_{\mathrm{FE}, \mathrm{FM}} \\
\lambda_{1}[\%]\end{array}$ & $n$ & $\begin{array}{c}e_{\mathrm{FE}, \mathrm{FM},}, \\
\lambda_{1}{ }^{\prime},[\%]\end{array}$ & $\begin{array}{c}e_{\mathrm{FE}, \mathrm{FM},}, \\
\lambda_{1}[\%]\end{array}$ \\
\hline $10 / 20 / 1.0$ & 663 & 0.03 & 0.19 & 2565 & 0.02 & 0.06 \\
\hline $20 / 35 / 1.5$ & 726 & 1.62 & 1.75 & 2817 & 0.54 & 0.59 \\
\hline $30 / 50 / 2.0$ & 759 & 4.19 & 4.25 & 2943 & 1.21 & 1.23 \\
\hline
\end{tabular}

\section{Finite ELEMENT ANALYsis (FEA) VS EXISTING ANALYTICAL METHODS}

FM is a useful approach, demonstrating physically the way proximity effects affect losses in $3 \mathrm{C}$ cables. It may also be quicker, in terms of the total set up and solution time, than FE method (FEM), without significant compromise in accuracy. FEM and FM are not limited to balanced loading conditions and are capable of treating unbalanced currents. They are not easily usable for hand calculations. Balanced conditions are typically assumed when calculating cable losses.

A 2-D FE solver is utilised in this section, firstly to review the accuracy of the existing analytical methods. Results from FM models, which have been derived based on (11), are also presented for completeness. As expected, they are in close agreement with FEA. Focus is made on $3 \mathrm{C}$ lead sheathed cable cores, which is the case in terms of the sheaths of OWF export cables. Two different assumptions are made with regard to the current density $J$ in phase conductors: uniform (no skin/ proximity effects) and non-uniform (skin/ proximity effects considered), namely $J_{\mathrm{u}}$ and $J_{\mathrm{nu}}$, respectively. Solid conductors are taken into account for simplicity, but the effect of stranded

$$
\mathbf{I}=\left[\mathbf{R}_{d}+j \frac{\omega \mu_{0}}{2 \pi} \mathbf{G}\right]^{-\mathbf{1}} \times \mathbf{M}^{T}\left[\mathbf{M}\left[\mathbf{R}_{d}+j \frac{\omega \mu_{0}}{2 \pi} \mathbf{G}\right]^{-\mathbf{1}} \mathbf{M}^{T}\right]^{-\mathbf{1}} \mathbf{I}^{\mathbf{c}}
$$


conductors, mostly used in practice, is studied in Section IVC1). Several geometrical parameters are considered to vary within representative ranges: conductor radius $r_{\mathrm{C}}$ from 10 to 30 $\mathrm{mm}$, sheath inner radius $r_{\mathrm{s} \text {,in }}$ from 15 to $60 \mathrm{~mm}$ and sheath thickness $t_{\mathrm{S}}$ from 1.0 to $4.0 \mathrm{~mm}$. To check individually for the influence of the variation of each parameter, the rest remain unchanged and equal to a moderate value each time.

Empirical, RFs are then presented, based on the parametric analysis done. These could be combined with the formulae of the current IEC version in order for its accuracy to be improved.

\section{A. Single-Point Bonding (SPB) Loss}

This section presents the results derived from four different methods, i.e. those suggested by Jackson and IEC, as well as FEA and FM. The effect of eddy currents up to $3^{\text {rd }}$ order is taken into consideration with respect to Jackson's method [3].

\section{1) Lead Sheaths:}

Lead sheaths are routinely used for subsea, export cables where the water-tightness of insulation is of crucial importance. Fig. 2 illustrates the effect of varying $r_{\mathrm{C}}$ on $\lambda_{1}$ " as calculated by four different methods. Since it is common to think of conductor cross-sectional areas (XSAs), the values $r_{\mathrm{C}}=10,20$ and $30 \mathrm{~mm}$ correspond, approximately, to 300,1000 and $2500 \mathrm{~mm}^{2}$. The results derived by the methods of IEC 60287 and Jackson [3] are in good agreement. This can be readily justified by the fact that the former, which is based on ERA's publication [5], successfully replaces the infinite series suggested by Jackson by means of the $\Delta_{1}$ factor shown in (6). Similar agreement occurs when FEA is applied considering $J_{\mathrm{u}}$ in phase conductors. However, once $J_{\text {nu }}$ is considered, significant discrepancies appear. It is noticeable in Fig. 2 that for decreasing $r_{\mathrm{C}}, J_{\mathrm{nu}}$ values tend closer to $J_{\mathrm{u}}$ ones, with the relative difference shrinking from $60 \%$ to $1 \%$.

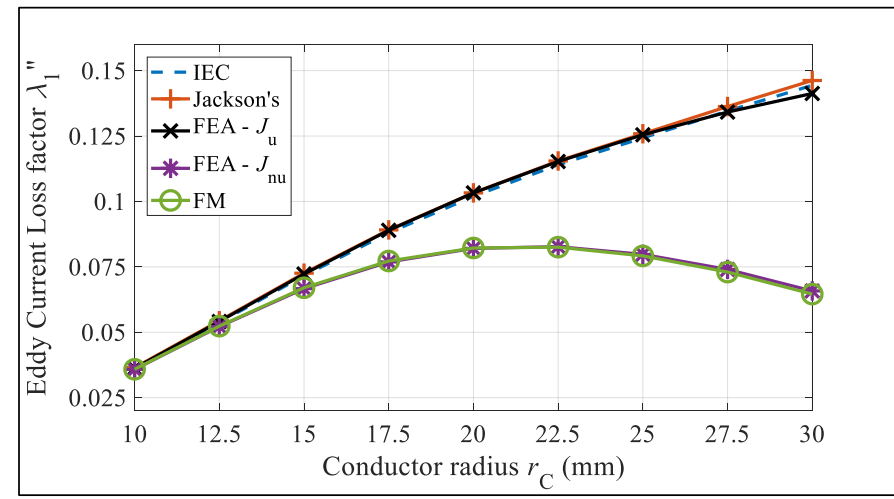

Fig. 2. Dependence of $\lambda_{1}$ " on $r_{\mathrm{C}}, r_{\mathrm{S}, \text { in }}=40 \mathrm{~mm}, t_{\mathrm{S}}=2.5 \mathrm{~mm}$ - Lead Sheaths.

For increasing $r_{\mathrm{S}, \text { in }}$ a similar trend is obtained; assuming a conductor with $r_{\mathrm{C}}=20 \mathrm{~mm}$ the difference drops from $43 \%$ down to $9 \%$. The more remote the sheath is from the nonuniform current source, the less it is affected by it. In other words, impact of the non-uniform conductor current is more significant with a thinner insulation. The effect of varying $t_{\mathrm{S}}$ on the divergence between $J_{\mathrm{u}}$ and $J_{\mathrm{nu}}$ results is even weaker compared to $r_{\mathrm{C}}$ and $r_{\mathrm{S} \text {,in. }}$.
2) Variation VS Sheath Resistivity, $\rho_{s}$ :

Materials besides lead are seldom used for submarine cable sheaths. However, it is worth noting the relative difference between $J_{\text {nu }}$ results and the existing analytical methods when varying $\rho_{\mathrm{S}}$. As shown in Fig. 3, this is kept nearly constant, about $28 \%$, for $\rho_{\mathrm{S}}$ values in between $\mathrm{Al}$ and lead materials [1] when a conductor of $r_{\mathrm{C}}=22.5 \mathrm{~mm}$ ( or $1400 \mathrm{~mm}^{2}$ ) is considered.

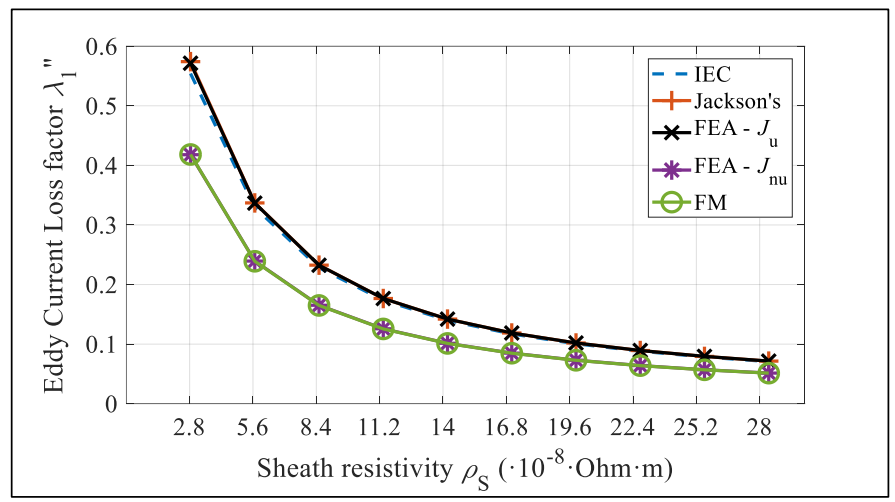

Fig. 3. Dependence of $\lambda_{1}$ " on $\rho_{S}, r_{\mathrm{C}}=22.5 \mathrm{~mm}, r_{\mathrm{S}, \text { in }}=40 \mathrm{~mm}, t_{\mathrm{S}}=2.0 \mathrm{~mm}$.

\section{3) Effect of the Proximity Effect in Conductors:}

Smaller conductors will see less intense skin and proximity effects, and hence a more uniform distribution of current. Although the skin effect can be strong in large conductors, the non-uniform current remains fairly symmetrical for widely spaced conductors. However, proximity effect is expected to further distort the current distribution, affecting the magnetic flux induced and hence the induced losses. This is neglected in the existing standards. To demonstrate the significance, the current distribution for $3 \times 1000 \mathrm{~mm}^{2}$ conductors is illustrated in Fig. 4. In particular, the phase average (average for a full cycle of $0.02 \mathrm{~s}$, so from phase $0^{\circ}$ to phase $360^{\circ}$ ) of current density $J_{\mathrm{C}}$ along $d_{\mathrm{C}}$ is shown. The spatial average of $J_{\mathrm{C}}$ is shifted about $40 \%$ from the center $\left(d_{\mathrm{C}}=20 \mathrm{~mm}\right)$ of the conductor and is closer to the neighboring one on the right, thus confirming the non-symmetry of current distribution.

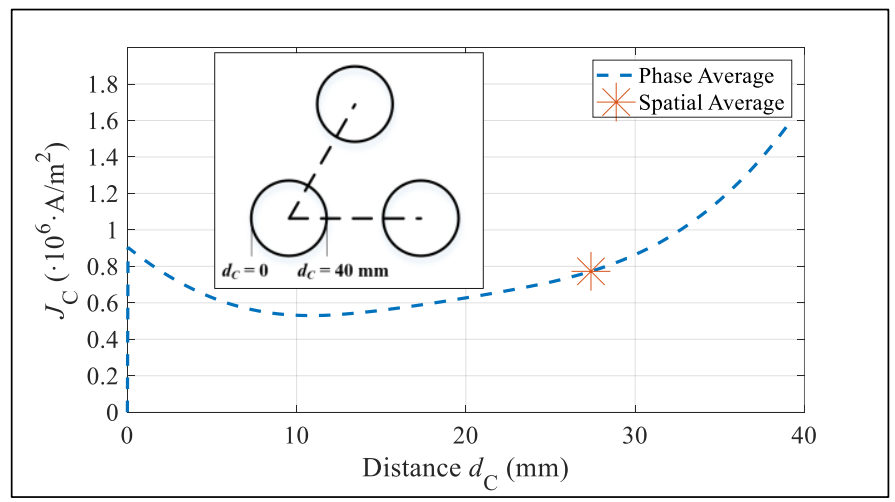

Fig. 4. Current density along $d_{\mathrm{C}}$ for $3 \times 1000 \mathrm{~mm}^{2}$ conductors.

Induced losses in sheaths depend on the magnetic flux along their circumference. Fig. 5 shows magnetic flux levels at phase angle $0^{\circ}$ along $L$ when two extreme conductor sizes $\left(150 \mathrm{~mm}^{2}\right.$ and $2000 \mathrm{~mm}^{2}$ ) are considered, both with $J_{\mathrm{nu}}$. The maximum difference reaches $0.79 \mathrm{mT}$ and the average is $0.38 \mathrm{mT}$, for 
matching current input $I$, axial separation $s$ and sheath geometry. The influence of proximity effects in conductors on eddy current loss is considered by neither Jackson [3] nor Parr [5]. As implied in the former's formulation, linear currents are assumed as the field sources. This appears to be a quite reasonable assumption for lower conductor sizes, but not so when higher sizes are considered, as illustrated in Fig. 5.

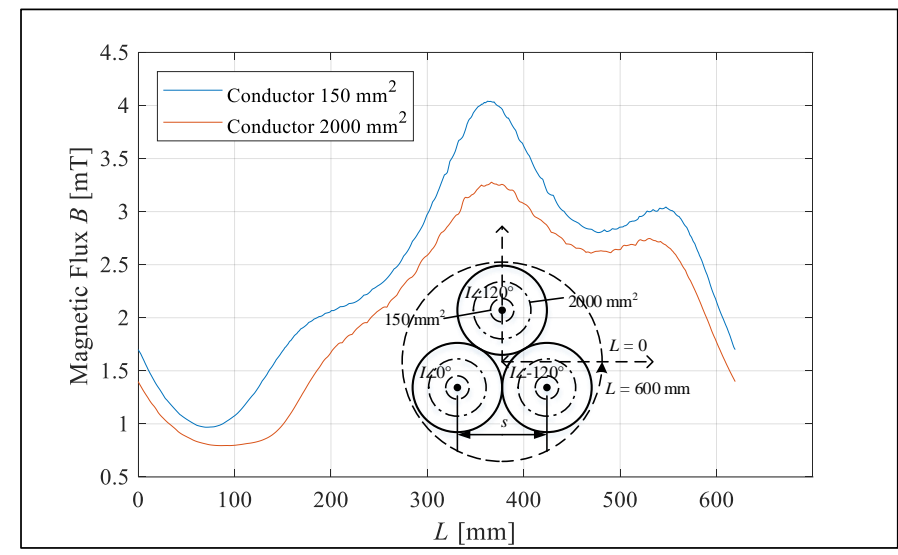

Fig. 5. Distribution of magnetic flux along the circumference above the 3 cores for $150 \mathrm{~mm}^{2}$ and $2000 \mathrm{~mm}^{2}$ conductors.

\section{4) Approximating Formulae Suggested:}

As shown in Section IV-A1), $r_{\mathrm{C}}$ and $r_{\mathrm{S}, \text { in }}$ appear to be the geometrical parameters mainly affecting the divergence between analytical and FE methods. RFs for single-point bonding losses are found, by minimizing the square difference of $\lambda_{1}$ " obtained with FEA and the corrected IEC method. The new value of $\lambda_{1}$ " is shown in (12).

$$
\lambda_{1, \mathrm{New}}^{\prime \prime}=R F_{\mathrm{SPB}} \cdot \lambda_{1, \mathrm{IEC}}^{\prime \prime}
$$

where $R F_{\mathrm{SPB}}=\lambda_{1, \text { New" }}$ " $\lambda_{1, \mathrm{IEC}}$ " is the Reductive Factor (RF) for single-point bonding case. Since $\lambda_{1, \mathrm{New}}$ " should be in close agreement with $\lambda_{1, \mathrm{FEA}} "$ (ideally $\lambda_{1, \mathrm{New}} "=\lambda_{1, \mathrm{FEA}}$ "), the ratio $\lambda_{1, \mathrm{FEA}} " \lambda_{1, \mathrm{IEC}}$ " is illustrated in Fig. 6 , where $X_{\mathrm{sc}}=r_{\mathrm{S}, \mathrm{in}}-r_{\mathrm{C}}$. The shapes of the curves suggest that the ratio could be approximated by polynomial functions of $r_{\mathrm{C}}$ and $X_{\mathrm{sc}}$.

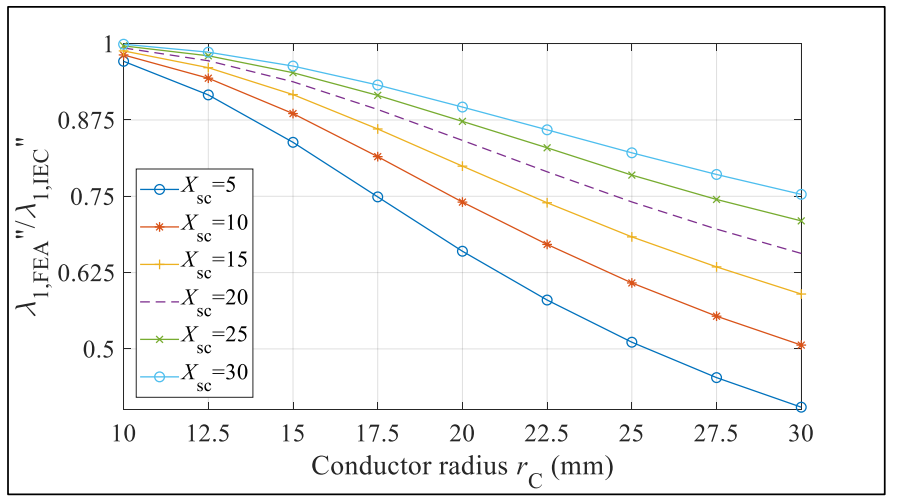

Fig. 6. Comparison of FEA and IEC results.

Results of both linear and polynomial of $3^{\text {rd }}$ order are shown in Table II, for certain indicative cable sizes. Better accuracy is obtained when the latter fitting is chosen, while sufficiently good correction is achieved with the former one, especially for larger cable sizes. $R$-square is also included for informative purposes.

TABLE II

RELATIVE DIFFERENCE OF THE CORRECTED IEC, SPB LOSS FACTOR VS FEA

\begin{tabular}{|c|c|c|}
\hline \multirow{2}{*}{$\begin{array}{c}r_{\mathrm{C}} / r_{\mathrm{S}, \mathrm{in}} / t_{\mathrm{S}} \\
{[\mathrm{mm}]}\end{array}$} & \multicolumn{2}{|c|}{$\frac{\lambda_{1, \mathrm{New}}^{\prime \prime}-\lambda_{1, \mathrm{FEA}}^{\prime \prime}}{\lambda_{1, \mathrm{FEA}}^{\prime \prime}} \cdot 100 \%$} \\
\cline { 2 - 3 } & Linear $(R$-square: 0.9239$)$ & $\begin{array}{c}3^{\text {rd }} \text { polynomial }(R- \\
\text { square: } 0.9985)\end{array}$ \\
\hline $10.0 / 20.0 / 1.0$ & $-6.0 \%$ & $-0.5 \%$ \\
\hline $20.0 / 35.0 / 1.5$ & $-3.3 \%$ & $-0.5 \%$ \\
\hline $30.0 / 50.0 / 2.0$ & $-4.6 \%$ & $-0.5 \%$ \\
\hline
\end{tabular}

The exact form of the RF formula derived is shown in (14) and (15) (see Appendix) for $3^{\text {rd }}$ order polynomial and linear approximation, respectively. Since $r_{\mathrm{C}}$ and $r_{\mathrm{S} \text {,in }}$ appear to mainly affect the divergence between IEC and FEA results, other parameters, e.g. conductor resistivity, $\rho_{\mathrm{C}}$, and $t_{\mathrm{S}}$, are assumed to have a constant, moderate value in the parametric analysis done. The applicability of (14) and (15) for different $\rho_{\mathrm{C}}$ and $t_{\mathrm{S}}$ values is considered in section IV-C2).

\section{B. Solid Bonding (SB) Losses}

This section presents results for solidly bonded sheaths, i.e. $\lambda_{1}$ ' plus $\lambda_{1}$ ", derived from IEC, FEA and FM calculations. Both FE and FM models do not distinguish circulating and eddy losses, whereas IEC considers them separately, as shown in (10). Results are presented for lead sheaths, while the effect of sheath conductivity is also studied.

\section{1)Lead Sheaths:}

The trends seen for lead sheaths resemble qualitatively those seen for single-point bonding loss regarding $r_{\mathrm{C}}, r_{\mathrm{S} \text {,in }}$ and $t_{\mathrm{S}}$ parameters. $r_{\mathrm{C}}$ appears to be the geometric parameter mainly affecting loss results: a maximum difference of $52 \%$ between FEA $-J_{\text {nu }}$ and IEC values is shown in Fig. 7. Increase in $r_{\text {S.in }}$ leads to a slight decrease of the divergence from $25 \%$ to $10 \%$, while impacts from $t_{\mathrm{s}}$ are again less significant.

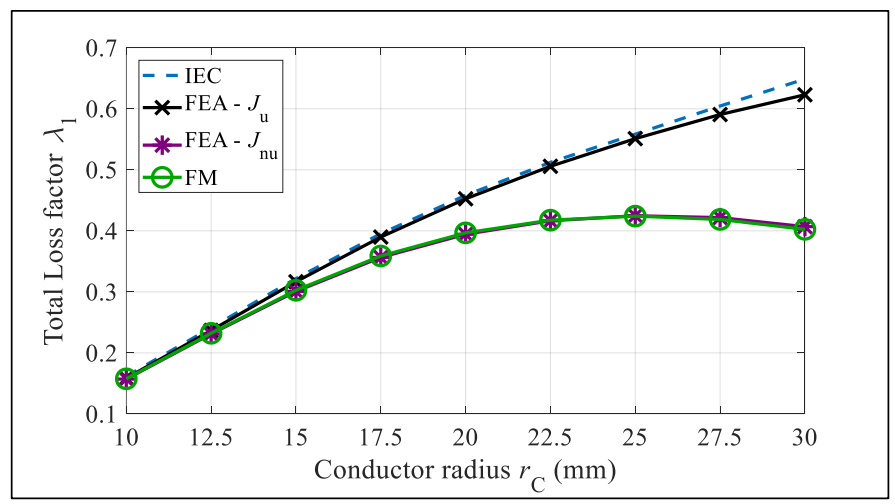

Fig. 7. Dependence of $\lambda_{1}$ on $r_{\mathrm{C}}, r_{\mathrm{S}, \mathrm{in}}=40 \mathrm{~mm}, t_{\mathrm{S}}=2.5 \mathrm{~mm}$ - Lead Sheaths.

2)Variation VS Sheath Resistivity, $\rho_{s}$ :

Although the influence of variation in $\rho_{\mathrm{S}}$ does not derive surprising results for $\lambda_{1}$ ", as shown in Fig. 3, more interesting is the dependence of $\lambda_{1}$ against $\rho_{\mathrm{S}}$, as shown in Fig. 8. For higher $\rho_{\mathrm{S}}$ values, the agreement between FEA $-J_{\mathrm{u}}$ values and IEC 
appears good enough. However, it becomes worse for lower $\rho_{\mathrm{S}}$, implying that the proximity effect in conductors is not the only factor at play. This is further discussed in the next subsection.

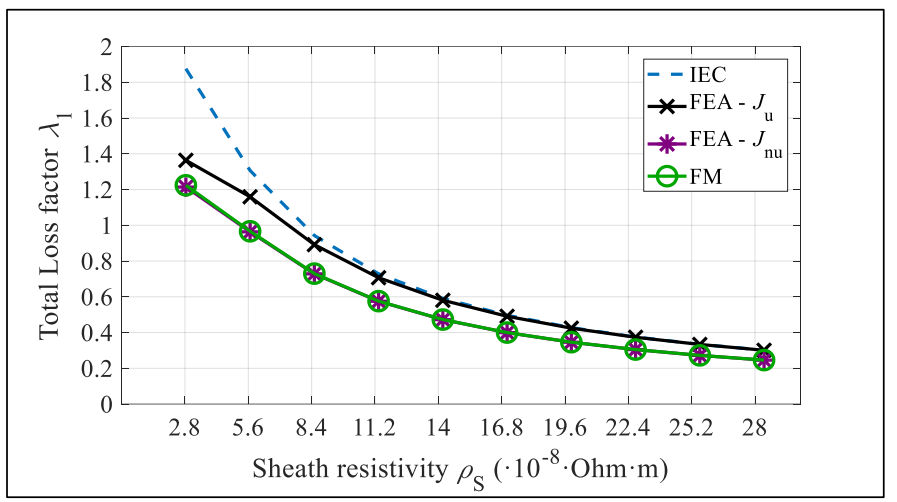

Fig. 8. Dependence of $\lambda_{1}$ on $\rho_{\mathrm{S}}, r_{\mathrm{C}}=22.5 \mathrm{~mm}, r_{\mathrm{S}, \text { in }}=40 \mathrm{~mm}, t_{\mathrm{S}}=2.0 \mathrm{~mm}$.

\section{3)Interpretation of Results - Effect of Cable Spacing:}

Besides the influence the proximity effect in conductors has on solid bonding losses, skin and proximity effects in sheaths themselves are modeled in FEA. Skin effect is fairly weak for the sheaths: calculated skin depths are about $33 \mathrm{~mm}$ (lead) and $12 \mathrm{~mm}(\mathrm{Al})$, much larger than the range of $t_{\mathrm{S}}$ values involved. Two identical 3C cable geometries are examined to further investigate the effect of distance $s$, on sheath resistance and circulating current, $I_{\mathrm{s}}$. Lead and $\mathrm{Al}$ sheaths of equal geometry are assumed to derive comparable results, while both $J_{\mathrm{u}}$ and $J_{\mathrm{nu}}$ are considered. Medium values for $r_{\mathrm{C}}$ and $r_{\mathrm{S} \text {,in }}$ are also assumed (20 $\mathrm{mm}$ and $35 \mathrm{~mm}$, respectively). Sheath resistance and current are extracted by FEA. Their ratios to the corresponding IEC values, namely $R_{\mathrm{FEA}} / R_{\mathrm{IEC}}$ and $I_{\mathrm{FEA}} / I_{\mathrm{IEC}}$, respectively, are considered and shown in Table III and Table IV.

TABLE III

EFFECT OF CABLE SPACING ON SHEATH RESISTANCE AND $I_{\mathrm{S}}$ - LEAD SHEATHS

\begin{tabular}{|c|c|c|c|c|}
\hline Cable Spacing $s$ & $\begin{array}{c}R_{\mathrm{FEA}} / \mathrm{R}_{\mathrm{IEC}} \\
-J_{\mathrm{u}}\end{array}$ & $\begin{array}{c}I_{\mathrm{FEA}} / \mathrm{I}_{\mathrm{IEC}}- \\
J_{\mathrm{u}}\end{array}$ & $\begin{array}{c}R_{\mathrm{FEA}} / \mathrm{R}_{\mathrm{IEC}} \\
-J_{\mathrm{nu}}\end{array}$ & $\begin{array}{c}I_{\mathrm{FEA}} / \mathrm{I}_{\mathrm{IEC}} \\
-J_{\mathrm{nu}}\end{array}$ \\
\hline $\begin{array}{c}d_{\text {core }} \text { (touching } \\
\text { formation) }\end{array}$ & 1.32 & 0.87 & 1.28 & 0.80 \\
\hline $1.5 \times d_{\text {core }}$ & 1.06 & 0.97 & 1.04 & 0.95 \\
\hline $3 \times d_{\text {core }}$ & 1.01 & 1.00 & 1.00 & 0.99 \\
\hline
\end{tabular}

TABLE IV

EFFECT OF CABLE SPACING ON SHEATH RESISTANCE AND $I_{\mathrm{S}}-$ AL SHEATHS

\begin{tabular}{|c|c|c|c|c|}
\hline Cable Spacing $s$ & $\begin{array}{c}R_{\mathrm{FEA}} / \mathrm{R}_{\mathrm{IEC}} \\
-J_{\mathrm{u}}\end{array}$ & $\begin{array}{c}I_{\mathrm{FEA}} / \mathrm{I}_{\mathrm{IEC}}- \\
J_{\mathrm{u}}\end{array}$ & $\begin{array}{c}R_{\mathrm{FEA}} / \mathrm{R}_{\mathrm{IEC}} \\
-J_{\mathrm{nu}}\end{array}$ & $\begin{array}{c}I_{\mathrm{FEA}} / \mathrm{I}_{\mathrm{IEC}}- \\
J_{\mathrm{nu}}\end{array}$ \\
\hline $\begin{array}{c}d_{\text {core }} \text { (touching } \\
\text { formation) }\end{array}$ & 1.31 & 0.78 & 1.27 & 0.73 \\
\hline $1.5 \times d_{\text {core }}$ & 1.05 & 0.93 & 1.04 & 0.92 \\
\hline $3 \times d_{\text {core }}$ & 1.01 & 0.99 & 1.00 & 0.99 \\
\hline
\end{tabular}

As shown, by reducing $s, R_{\mathrm{FEA}} / R_{\mathrm{IEC}}$ increases and $I_{\mathrm{FEA}} / I_{\mathrm{IEC}}$ decreases. IEC results are in a good agreement with FE ones for spaced cables, whereas the situation appears different for cores being in close proximity one another; the increase in $R_{\mathrm{FEA}} / R_{\mathrm{IEC}}$ implies that $I_{\mathrm{S}}$ is not uniformly distributed along sheath.

For Lead sheaths, FEA and IEC sheath losses appear alike each other when $J_{\mathrm{u}}$ is considered. The reduction of current ratio is compensated by the respective increase in resistance ratio, thus leading to nearly equal losses. Lower $I_{\mathrm{S}}$ values are recorded once $J_{\mathrm{nu}}$ is considered, because of the lower magnetic field actually induced. Although higher $R_{\mathrm{S}}$ values are also seen in this case, the current dominates in the loss calculation $\left(W_{\mathrm{S}}=I_{\mathrm{S}}{ }^{2} R_{\mathrm{S}}\right)$, thus leading to lower losses.

$J$ in conductors seems to affect the current ratio in terms of Al sheaths, leading to lower losses. However, the current ratio is significantly lower for $J_{\mathrm{u}}$ assumption and the increase in resistance ratio is not capable of compensating the respective decrease in the current ratio. Due to the higher conductivity of $\mathrm{Al}$, higher eddy currents occur, which cancel out locally the overall circulating current $\left(I_{\mathrm{S}}\right)$ to a greater extent, thus yielding a less uniform $J$ along sheaths' circumference and a stronger proximity effect.

\section{4)Approximating Formulae Suggested:}

Similar analysis to subsection IV-A4) is undertaken for solid bonding losses, with the same geometrical parameters being varied to obtain RFs. The new value of $\lambda_{1}$ is shown in (13). Results of both linear and polynomial of $3^{\text {rd }}$ order are shown in Table $\mathrm{V}$, for certain indicative cable sizes. Better accuracy is obtained when the latter fitting is chosen, while sufficiently good correction is achieved with the former one. The relevant formulae for $3^{\text {rd }}$ order polynomial and linear are shown in (14) and (15), respectively, in Appendix. Similar checks to those of section IV-A4) are done and presented in section IV-C2).

$$
\lambda_{1, \mathrm{New}}=R F_{\mathrm{SB}} \cdot \lambda_{1, \mathrm{IEC}}
$$

TABLE V

RELATIVE DIFFERENCE OF THE CORRECTED IEC, SB FACTOR VS FEA

\begin{tabular}{|c|c|c|}
\hline \multirow{2}{*}{$\begin{array}{l}r_{\mathrm{C}} / r_{\mathrm{S}, \mathrm{in}} / t_{\mathrm{S}} \\
{[\mathrm{mm}]}\end{array}$} & \multicolumn{2}{|c|}{$\frac{\lambda_{1, \mathrm{New}}-\lambda_{1, \mathrm{FEA}}}{\lambda_{1, \mathrm{FEA}}} \cdot 100 \%$} \\
\hline & Linear ( $R$-square: 0.9237$)$ & $\begin{array}{c}3^{\text {rd }} \text { polynomial }(R \text {-square: } \\
0.9991)\end{array}$ \\
\hline $10.0 / 20.0 / 1.0$ & $-3.3 \%$ & $-0.5 \%$ \\
\hline $20.0 / 35.0 / 1.5$ & $-1.9 \%$ & $0.4 \%$ \\
\hline $30.0 / 50.0 / 2.0$ & $-2.1 \%$ & $0.1 \%$ \\
\hline
\end{tabular}

\section{Review of the Assumptions Made}

\section{1)Effect of Conductor Structure:}

Solid conductors, which are assumed in the present paper, are less often used in practice, mainly due to mechanical reasons. Stranded conductors usually have uneven dc resistance throughout their cross-section, because of the different lay length applied between the various layers of strands during the twisting process. Therefore, proximity effect is expected to be slightly weaker compared with solid conductors.

The lay length of outer layers depends on the production process of each manufacturer. The assumption of $10 \%$ longer outer strands is made in this section. In addition, to avoid simulating the conductor strand by strand, the electrical conductivity of the conductor is varied as a linear function of radius. Considering $r_{\mathrm{C}}=20 \mathrm{~mm}$ and $t_{\mathrm{S}}=2.5 \mathrm{~mm}$, eddy current loss appears $1 \%$ higher once variable conductivity is assumed, while at the same moment it is $26 \%$ higher when $J_{\mathrm{u}}$ is assumed. Therefore, the assumption of solid conductors appears to be 
adequately reasonable in terms of its effect on sheath loss. It is noted that overlength values higher than 1.1 are not often met in practice.

\section{2)Effect of $t_{S}, t_{J}$ and $\rho_{C}$ :}

Certain assumptions are made for the derivation of both $R F_{\mathrm{SPB}}$ and $R F_{\mathrm{SB}}$ for the sake of simplicity. In particular, a constant, moderate value is considered for $t_{\mathrm{S}}$, while the jacket over the sheath is supposed to be of thickness $t_{\mathrm{J}}=t_{\mathrm{S}}$. Hence, the applicability of (14), (15) must be checked for variable $t_{\mathrm{S}}, t_{\mathrm{J}}$, within reasonable margins. $r_{\mathrm{C}}, X_{\mathrm{sc}}$ are varied for each pair of $t_{\mathrm{S}}$, $t_{\mathrm{J}}$ values and the average of the relative difference $\left(\lambda_{1, \mathrm{New}}-\right.$ $\left.\lambda_{1, \mathrm{FEA}}\right) / \lambda_{1, \mathrm{FEA}}$, namely $e_{\mathrm{avg}}$, is recorded in this section. Results are shown in Table VI and Table VII. $e_{\mathrm{avg}}$ in terms of $R F_{\mathrm{SPB}}-$ FEA appears to be consistent enough and not much affected by $t_{\mathrm{J}}, t_{\mathrm{S}}$. That for $R F_{\mathrm{SB}}-$ FEA increases for higher $t_{\mathrm{S}}, t_{\mathrm{J}}$, while at the same time $e_{\text {avg }}$ for IEC - FEA decreases. Although the RFs appear to work less effectively for some extreme cases, cables with such thick sheaths and even thicker jackets are not possible in practice.

TABLE VI

AVERAGE RELATIVE DIFFERENCE FOR VARIOUS GEOMETRIES - SPB LOSS

\begin{tabular}{|c|c|c|c|c|c|c|}
\hline & \multicolumn{2}{|c|}{$e_{\text {avg }}[\%], t_{\mathrm{J}}=2 \times t_{\mathrm{S}}$} & \multicolumn{3}{c|}{$e_{\text {avg }}\left[\%, t_{\mathrm{J}}=3 \times t_{\mathrm{S}}\right.$} \\
\hline \multirow{2}{*}{$t_{\mathrm{S}}[\mathrm{mm}]$} & $\begin{array}{c}\text { IEC }- \\
\text { FEA }\end{array}$ & $\begin{array}{c}(15)- \\
\text { FEA }\end{array}$ & $\begin{array}{c}(14)- \\
\text { FEA }\end{array}$ & $\begin{array}{c}\text { IEC }- \\
\text { FEA }\end{array}$ & $\begin{array}{c}(15)- \\
\text { FEA }\end{array}$ & $\begin{array}{c}(14)- \\
\text { FEA }\end{array}$ \\
\hline 1.0 & 36.4 & 4.2 & 1.4 & 36.6 & 4.6 & 2.1 \\
\hline 2.0 & 36.8 & 4.1 & 1.7 & 37.6 & 4.2 & 2.3 \\
\hline 3.0 & 36.7 & 4.0 & 1.7 & 37.7 & 4.1 & 2.4 \\
\hline 4.0 & 36.3 & 3.8 & 1.6 & 37.3 & 4.0 & 2.2 \\
\hline
\end{tabular}

TABLE VII

AVERAGE RELATIVE DIFFERENCE FOR VARIOUS GEOMETRIES - SB LOSS

\begin{tabular}{|c|c|c|c|c|c|c|}
\hline & \multicolumn{3}{|c|}{$e_{\text {avg }}\left[\%, t_{\mathrm{J}}=2 \times t_{\mathrm{S}}\right.$} & \multicolumn{3}{c|}{$e_{\text {avg }}\left[\%, t_{\mathrm{J}}=3 \times t_{\mathrm{S}}\right.$} \\
\hline $\begin{array}{c}t_{\mathrm{S}} \\
{[\mathrm{mm}]}\end{array}$ & $\begin{array}{c}\text { IEC }- \\
\text { FEA }\end{array}$ & $\begin{array}{c}(15)- \\
\text { FEA }\end{array}$ & $\begin{array}{c}(14)- \\
\text { FEA }\end{array}$ & $\begin{array}{c}\text { IEC }- \\
\text { FEA }\end{array}$ & $\begin{array}{c}(15)- \\
\text { FEA }\end{array}$ & $\begin{array}{c}(14)- \\
\text { FEA }\end{array}$ \\
\hline 1.0 & 21.1 & 3.1 & 1.5 & 19.6 & 2.9 & 0.9 \\
\hline 2.0 & 18.2 & 2.7 & 1.2 & 15.9 & 3.7 & 3.0 \\
\hline 3.0 & 16.2 & 3.6 & 2.7 & 13.3 & 5.7 & 4.8 \\
\hline 4.0 & 14.6 & 5.0 & 4.1 & 11.4 & 7.2 & 6.3 \\
\hline
\end{tabular}

Besides the effect of $t_{\mathrm{S}}, t_{\mathrm{J}}$, that of conductor resistivity, $\rho_{\mathrm{C}}$, is checked. $\rho_{\mathrm{C}}$ is selected equal to the average value between that of $\mathrm{Cu}$ conductors at $20^{\circ} \mathrm{C}, \rho_{\mathrm{Cu} \_20^{\circ}}$, and $\mathrm{Al}$ at $90^{\circ} \mathrm{C}, \rho_{\mathrm{Al} \_90^{\circ}},[1]$ during the derivation of the RFs. However, the higher $\rho_{\mathrm{C}}$, the stronger the proximity effect of the conductor and vice versa; thus, this assumption is also worth reviewing. Results are shown in Table VIII. Values for the mean of $\rho_{\mathrm{Cu} \_20^{\circ}}$ and $\rho_{\mathrm{Al} \_90^{\circ}}$ are also given as a reference. RFs give better results when tested for $\rho_{\mathrm{Cu} \_20^{\circ}}$, since the proximity effect is more intense and $e_{\mathrm{avg}}$ between IEC - FEA is higher. On the contrary, they give relatively worse results for $\rho_{\mathrm{Al} \_90^{\circ}}$, since the proximity effect is less intense and $e_{\mathrm{avg}}$ between IEC - FEA is lower. In any case, RFs provide results closer to FEA.

\section{EFFECT ON THERMAL RATING}

The results shown in the present study suggest lower induced losses compared to the formulae provided by IEC 60287 for lead sheathed cable cores laid in close trefoil arrangement. The thermal impact of this reduction is assessed in the present section, considering three 1C Lead sheathed cores in "typical" subsea installation conditions and solidly bonded sheaths.

TABLE VIII

AVERAGE RELATIVE DIFFERENCE FOR VARIOUS CONDUCTOR RESISTIVITIES

\begin{tabular}{|c|c|c|c|c|c|c|}
\hline & \multicolumn{2}{|c|}{$e_{\text {avg }}[\%]$, SPB Loss } & \multicolumn{2}{c|}{$e_{\text {avg }}[\%]$, SB Losses } \\
\hline$\rho_{\mathrm{C}}$ & $\begin{array}{c}\text { IEC }- \\
\text { FEA }\end{array}$ & $\begin{array}{c}(15)- \\
\text { FEA }\end{array}$ & $\begin{array}{c}(14)- \\
\text { FEA }\end{array}$ & $\begin{array}{c}\text { IEC }- \\
\text { FEA }\end{array}$ & $\begin{array}{c}(15)- \\
\text { FEA }\end{array}$ & $\begin{array}{c}(14)- \\
\text { FEA }\end{array}$ \\
\hline$\rho_{\text {Cu_20 }{ }^{\circ} \mathrm{C}}+\rho_{\mathrm{Al}_{\text {_90 }}{ }^{\circ} \mathrm{C}}$ \\
\hline 2 & 33.2 & 5.3 & 0.7 & 19.4 & 3 & 0.3 \\
\hline$\rho_{\text {Cu_20 }}$ & 42.0 & 7.6 & 5.6 & 23.1 & 3.8 & 3.0 \\
\hline$\rho_{\text {Al_90 }}$ & 22.1 & 8.0 & 7.0 & 14.5 & 4.6 & 3.6 \\
\hline
\end{tabular}

Several researchers have already dealt with FE modeling of 3C cables with magnetic wire armor, such as Goddard [15], Bremnes [16] and da Silva [17]. They all agree to the point that circulating currents are not expected in armor wires. The approach of series connection between all armor wires used by [16] and [17] is applied here to ensure no circulating currents in the non-magnetic armor. Three indicative cable sizes as shown in Table IX are simulated with and without non-magnetic armoring above the 3 cores. The changes in sheath losses are lower than $0.5 \%$, thus implying that the presence of nonmagnetic armor has almost no effect on induced losses in sheaths. Similar results about the difference in $\lambda_{1}$ are presented by Benato in [18], based on the 3-D analysis performed for 3C cables with stainless steel and without armor. Consequently, the non-magnetic armor may be neglected for simplicity when sheath loss is of interest.

For each cable size considered, sheath losses calculated by IEC 60287 and FE models are used, while conductor loss from FEA is imported in both cases. The cable is considered buried $1 \mathrm{~m}$ deep in soil of thermal resistivity $0.7 \mathrm{KmW}^{-1}$ at $15^{\circ} \mathrm{C}$ ambient temperature under steady-state conditions. Eddy current loss $\left(\lambda_{1}\right.$ ") is accounted for by the FE models, whereas two cases are considered for IEC calculations; those ignoring and including $\lambda_{1}$ ", respectively. The corresponding results are illustrated in Table IX.

TABLE IX

MAXIMUM CONDUCTOR TEMPERATURE: SHEATH LOSSES CALCULATED BY FEA AND IEC FOR NON-MAGNETIC ARMOURED 3C CABLES

\begin{tabular}{|c|c|c|c|c|c|}
\hline $\begin{array}{c}r_{\mathrm{C}} / r_{\mathrm{S}, \mathrm{in}} / t_{\mathrm{S}} \\
{[\mathrm{mm}]}\end{array}$ & $\begin{array}{c}\mathrm{FE} \\
\text { models } \\
{\left[{ }^{\circ} \mathrm{C}\right]}\end{array}$ & $\begin{array}{c}\mathrm{IEC} / \\
\lambda_{1}{ }^{\circ}=0 \\
{\left[{ }^{\circ} \mathrm{C}\right]}\end{array}$ & $\begin{array}{c}\Delta \theta_{1} \\
{\left[{ }^{\circ} \mathrm{C}\right]}\end{array}$ & $\begin{array}{c}\mathrm{IEC} / \\
\lambda_{1}{ }^{\prime} \neq 0 \\
{\left[{ }^{\circ} \mathrm{C}\right]}\end{array}$ & $\begin{array}{c}\Delta \theta_{2} \\
{\left[{ }^{\circ} \mathrm{C}\right]}\end{array}$ \\
\hline $10.0 / 20.0 / 1.5$ & 90.0 & 89.7 & 0.3 & 90.4 & -0.4 \\
\hline $20.0 / 35.0 / 2.5$ & 90.0 & 91.4 & -1.4 & 96.5 & -6.5 \\
\hline $30.0 / 50.0 / 3.5$ & 90.0 & 97.2 & -7.2 & 109.2 & -19.2 \\
\hline
\end{tabular}

As shown in Table IX, $\Delta \theta_{1}$, which occurs from the subtraction between $2^{\text {nd }}$ and $3^{\text {rd }}$ columns of Table IX, is low for small and medium cable sizes. However, FE results are about $7^{\circ} \mathrm{C}$ (or $8 \%$ ) lower for larger cable sizes due to the IEC overestimating the losses. The FEA includes fully the eddy currents and resulting proximity effects, the extent of which is outweighed by the reduction in circulating current loss. As seen by $\Delta \theta_{2}$ values, which occur from the subtraction between $2^{\text {nd }}$ and $5^{\text {th }}$ columns, IEC can become overly conservative if including $\lambda_{1}$ ", particularly for larger cable sizes. 
$R F_{-} 3 r d\left(r_{C}, X_{s c}\right)=p_{00}+p_{10} X_{s c}+p_{01} r_{C}+p_{20} X_{s c}{ }^{2}+p_{11} X_{s c} r_{C}+p_{02} r_{C}^{2}+p_{30} X_{s c}{ }^{3}+p_{21} X_{s c}{ }^{2} r_{C}+p_{12} X_{s c} r_{C}^{2}+p_{03} r_{C}^{3}$

A threshold above which the RFs are significant may be identified from the present analysis; based on Fig. 7, total solid bonding losses appear to be about $14 \%$ lower than IEC predicts for a conductor size of $r_{\mathrm{C}}=20 \mathrm{~mm}$ or, approximately, $1000 \mathrm{~mm}^{2}$. The temperature difference for this case starts to become significant (above $1^{\circ} \mathrm{C}$ ), as shown by $\Delta \theta_{1}$ and $\Delta \theta_{2}$ values of Table IX. Although the value $r_{\mathrm{C}}=30 \mathrm{~mm}$ or, approximately, $2500 \mathrm{~mm}^{2}$ corresponds to the higher standardized conductor size [19], this is still used in practice. Milliken conductors are not easily manageable for large subsea projects, mainly because of the increased cable weight and the difficulty in making them watertight enough.

\section{CONCLUSION}

The work presented in this paper reviews the formulae for induced losses in sheaths used by IEC 60287 for cables in trefoil touching formation, making focus on three-core (3C) submarine cables with non-magnetic armor. The present Standard method implies uniform currents in the conductors and considers only the sheath dc resistance when calculating $\lambda_{1}$.

FM and FEM are employed in order to effectively represent proximity effects and appear to be in a good agreement each other. Both FM and FE models show a good agreement on eddy current loss ( $\lambda_{1}$ " factor) with the existing analytical formulae for smaller conductors. When larger conductors are assumed, the discrepancy is kept fairly low on the condition that uniform current density in conductors is considered. The current distribution in conductors affects also solid bonding losses. Although $\lambda_{1}$ " factor is ignored by IEC 60287 for solidly bonded sheaths, it can overestimate conductor temperature by up to $7^{\circ} \mathrm{C}$ $(8 \%)$, for cables with larger conductors. Even higher overestimation occurs if $\lambda_{1}$ " is added into IEC 60287 calculations. This is particularly important for projects which employ non-magnetically armored subsea cables. In subsea projects the use of Milliken conductors to reduce the proximity effect in conductors is technically challenging where waterblocking is needed.

Approximating formulae are derived based on the parametric study. The RFs are suitable for quick calculations and may be used in order to improve the accuracy of IEC Standard. Their application becomes important for conductor sizes of $1000 \mathrm{~mm}^{2}$ and above and their thermal effect becomes higher when even larger sizes are considered.

\section{APPENDIX}

Approximating formulae are suggested to improve the accuracy of the current $\lambda_{1, \mathrm{IEC}}$ " and $\lambda_{1, \mathrm{IEC}}$ formulae used for three $1 \mathrm{C}$ cables in trefoil touching formation by IEC 60287 . For both $\lambda_{1, \text { New }}$ and $\lambda_{1, \text { New }}$ in Lead sheaths the same form is extracted, though with different coefficients. The relevant reduction factors are given in (14) and (15) for $3^{\text {rd }}$ order polynomial and linear approximation, respectively. The values for coefficients are illustrated in Table $\mathrm{X}$, depending on bonding arrangement and approximating approach.

$$
R F_{\_} \operatorname{lin}\left(r_{C}, X_{s c}\right)=p_{00}+p_{10} \cdot X_{s c}+p_{01} \cdot r_{C}
$$

TABLE $X$

COEFFICIENTS FOR RF FORMULAE SUGGESTED FOR SPB AND SB LOSSES OF LEAD SHEATHED POWER CORES

\begin{tabular}{|c|c|c|c|c|}
\hline & \multicolumn{2}{|c|}{ Single-Point Bonding $-\lambda_{1, \text { New }}^{\prime \prime}$} & \multicolumn{2}{c|}{ Solid Bonding $-\lambda_{1, \mathrm{New}}$} \\
\hline Formula & $(15)$ & $(14)$ & $(15)$ & $(14)$ \\
\hline$p_{00}$ & 1.037 & 1.083 & 1.041 & 1.02 \\
\hline$p_{10}$ & $8.125 \mathrm{e}-3$ & $-6.734 \mathrm{e}-3$ & 0.00398 & $-3.048 \mathrm{e}-3$ \\
\hline$p_{01}$ & -0.0191 & $1.112 \mathrm{e}-3$ & -0.0128 & $4.516 \mathrm{e}-3$ \\
\hline$p_{20}$ & N/A & $-1.851 \mathrm{e}-4$ & N/A & $-1.133 \mathrm{e}-4$ \\
\hline$p_{11}$ & N/A & $1.585 \mathrm{e}-3$ & N/A & $7.076 \mathrm{e}-4$ \\
\hline$p_{02}$ & N/A & $-1.993 \mathrm{e}-3$ & N/A & $-1.258 \mathrm{e}-3$ \\
\hline$p_{30}$ & N/A & $4.253 \mathrm{e}-6$ & N/A & $2.956 \mathrm{e}-6$ \\
\hline$p_{21}$ & N/A & $-1.239 \mathrm{e}-5$ & N/A & $-8.957 \mathrm{e}-6$ \\
\hline$p_{12}$ & N/A & $-1.325 \mathrm{e}-5$ & N/A & $4.999 \mathrm{e}-8$ \\
\hline$p_{03}$ & N/A & $3.489 \mathrm{e}-5$ & N/A & $1.828 \mathrm{e}-5$ \\
\hline
\end{tabular}

\section{ACKNOWLEDGMENT}

D. Chatzipetros would like to thank his colleague and friend Dr. Andreas I. Chrysochos for his comments and suggestions in preparing this paper.

\section{REFERENCES}

[1] "Electric cables - calculation of the current rating - part 1-1: Current rating equations (100\% load factor) and calculation of losses - general.", IEC 60287-1-1, 2014-11.

[2] G. J. Anders, "Joule Losses in Screens, Armor and Pipes", in Rating of Electric Power Cables, IEEE Press, 1997, ch. 8, pp 1-80.

[3] R. L. Jackson, "Eddy-Current Losses in Unbonded Tubes", Proc. IEE, Vol. 122, No 5, May 1975.

[4] F. W. Carter, "Note on Losses in Cable Sheaths", Math. Proc. Camb. Philos. Soc., Vol. 23, pp.65-73, 1927.

[5] R. G. Parr, "Formulae for Eddy-Current Loss Factors in Single-Point or Cross-Bonded Cable Sheaths", ERA, Surrey, UK, Rep. 79-97, 1979.

[6] P. G. Heyda, G. E. Kitchie, J. E. Taylor, "Computation of eddy-current losses in cable sheaths and busbar enclosures", Proc. IEE, Vol. 120, No 4, April 1973.

[7] A. H. M. Arnold, "Eddy Current Losses in Multi-Core Paper-Insulated Lead-Covered Cables, Armoured and Unarmoured, Carrying Balanced Three-Phase Current.”, BEAIRA, London, UK, Rep. F/T132, 1939.

[8] A. H. M. Arnold, "The Theory of Sheath Losses in Single-Conductor LeadCovered Cables", Journal of IEE, Vol. 67, Issue: 384, December 1928.

[9] N. Kovač, G. J. Anders, "Sheath Loss Factors Taking Into Account the Proximity Effect for a Cable Line in a Touching Flat Formation", IEEE Trans. Power Del., Vol. 30, No. 3, June 2015.

[10]K. Ferkal, M. Poloujadoff, E. Dorison, "Proximity Effect and Eddy Current Losses in Insulated Cables", IEEE Trans. Power Del., Vol. 11, No. 3, July 1996.

[11]E. Comellini, A. Invernizzi, G. Manzoni, "A Computer Program for Determining Electrical Resistance and Reactance of Any Transmission Line”, ICC of the IEEE Power Eng. Soc., San Francisco, Calif, July 1972.

[12]N. Kovač, N. Grulovic-Pavljanic, A. Kukavica, "Generated Heat Within Power Cable Sheaths per Unit Time and Volume", App. Therm. Eng., Vol. 52, pp 90-96, November 2012

[13]W. Moutassem, G. J. Anders, "Calculation of the Eddy Current and Hysteresis Losses in Sheathed Cables Inside a Steel Pipe", IEEE Trans. Power Del., Vol. 25, No. 4, October 2010.

[14]D. Labridis, P. Dokopoulos, "Finite Element Computation of Field, Losses and Forces in a Three-Phase Gas Cable with Non-Symmetrical Conductor Arrangement", IEEE Trans. Power Del., Vol. 3, No. 4, October 1988. 
[15]K. F. Goddard, James A. Pilgrim, Richard Chippendale, and Paul L. Lewin, "Induced Losses in Three-Core SL-Type High-Voltage Cables", IEEE Trans. Power Del, Vol. 30, No. 3, June 2015.

[16] J. J. Bremnes, G. Evenset, R. Stølan, "Power Loss And Inductance Of Steel Armoured Multi-Core Cables: Comparison Of IEC Values With "2,5D" FEA Results And Measurements." B1-116, CIGRE 2010.

[17]F. M. F. da Silva, T. Ebdrup, C. L. Bak, C. F. Jensen (2016). "Understanding Losses in Three Core Armoured Submarine Cables", B1304, Cigré 2016.

[18]R. Benato, S. D. Sessa, "A New Multiconductor Cell Three-Dimension Matrix-Based Analysis Applied to a Three-Core Armoured Cable", IEEE Trans. Power Del, Vol. 33, No. 4, August 2018.

[19] “Conductors of insulated cables", IEC 60228, 2004-11.

\section{BIOGRAPHIES}

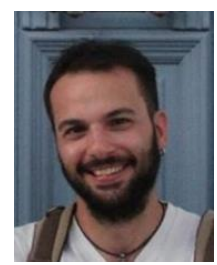

Dimitrios Chatzipetros received the Dipl. Eng. degree from the School of Electrical and Computer Engineering at the National Technical University of Athens, Greece, in 2012. His research interests include modelling aspects of High Voltage equipment, such as Field Analysis for Insulators and Multiphysics Analysis for Cables.

$\mathrm{He}$ works as a Senior Design Engineer in Cablel ${ }^{\circledR}$ Hellenic Cables S.A., Viohalko Group. He is currently pursuing the Ph.D. degree in Electrical Power Engineering at the University of Southampton, Southampton, U.K., while is actively involved as the Greece member of Cigré Working Group B1.64 "Evaluation of Losses in Armoured Three Core Power Cables".

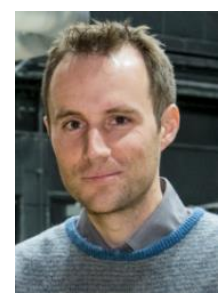

James A. Pilgrim (M'09, SM'17) received the Bachelor's degree in electrical engineering from the School of Electronics and Computer Science at the University of Southampton in 2007. He joined the staff of the University of Southampton in 2007 as a Research Assistant, gaining his PhD in 2011. He joined the academic staff of the University in 2012. His research interests include all aspects of high voltage cables and associated insulation systems. He is currently the Treasurer of the UKRI Chapter of the IEEE DEIS and Chair of the DEIS Technical Committee on Smart Grid. He is actively involved in the development of current rating methodologies, acting as the UK member of IEC TC 20 WG19 (Current Rating and Short Circuit Limits of Cables) and Cigre Working Groups B1.35 "Guide to rating calculations" and B1.56 "Current rating verification". 